\title{
Single-Phase Percutaneous Recanalization of Malignant Bile Duct Obstructions with a Covered Stent Graft
}

\author{
Perkutane Rekanalisation von malignen DHC \\ Gallengangsobstruktionen mit einer gecoverten \\ Stentprothese im einzeitigen Verfahren
}

Authors

Affiliations
F. Scheer ${ }^{1}$, C. Wissgott ${ }^{1}$, C. W. Lüdtke' ${ }^{1}$, C. Niessen ${ }^{2}$, P. Kamusella' ${ }^{1}$ P. Wiggermann ${ }^{2}$, R. Andresen ${ }^{1}$

Institute of Diagnostic and Interventional Radiology/Neuroradiology, Westkuestenklinikum Heide, Academic Teaching Hospital of the Universities of Kiel, Luebeck and Hamburg, Heide

2 Institute of Radiology, University Hospital Regensburg

\section{Key words}

bile ducts

bile duct radiography

- stents

drainage

- interventional procedures

- percutaneous received 14.5.2013

accepted 23.8.2013

Bibliography

DOI http://dx.doi.org/

10.1055/s-0033-1355552

Published online: 18.10.2013

Fortschr Röntgenstr 2014; 186: 394-399 ๑ Georg Thieme Verlag KG Stuttgart - New York . ISSN 1438-9029

\section{Correspondence}

\section{Dr. Fabian Scheer}

Institute of Diagnostic and Interventional Radiology/

Neuroradiology,

Westkuestenklinikum Heide,

Academic Teaching Hospital of

the Universities of Kiel, Luebeck and Hamburg

Esmarchstraße 50

25746 Heide

Tel.: ++49/4 81/785703595

Fax: ++ 49/481/7852409

FScheer@wkk-hei.de

\section{Abstract \\ $\nabla$}

Purpose: The aim of this study was to evaluate the benefit of a percutaneous transhepatic biliary drainage (PTCD) endoprothesis in the case of patients with malignant occlusion of the common bile duct (CBD).

Materials and Methods: 32 patients (mean age $72 \pm 13$ years) were treated with an endoprosthesis (VIABIL; M. L. GORE \& ASSOCIATES, INC., USA) due to failed attempts of endoscopic retrograde cholangiopancreatography (ERCP) in the case of malignant occlusion of the CBD.

Results: The technical success rate was $96.9 \%$. In one patient the probing of an intrahepatic bile duct was impossible. Two major complications (bleeding, liver abscess) were successfully treated with appropriate measures. The bilirubin level did not significantly decrease immediately after intervention (13.2 \pm $6.5 \mathrm{mg} / \mathrm{dl} ; \mathrm{p}>0.05$ ). However, the follow-up displayed a highly significant decrease of bilirubin to $6.0 \pm 7.4 \mathrm{mg} / \mathrm{dl} ; \mathrm{p}<0.05$ ). The endoprosthesis was extended with bare metal NITINOL stents in 9 patients. The mean survival time of the patient group was $64 \pm 28$ days (range 2 - 250 days).

Conclusion: The implantation of an endoprosthesis proved to be an option with high technical success, a low complication rate and good benefit in our patients with malignant bile duct obstruction in palliative therapy situations.

Key Points:

- The primary objective in the case of malignant bile duct obstruction is the treatment of jaundice.

- After failed endoscopic recanalization of the bile ducts, transhepatic biliary drainage is desirable.
- An ePTFE-FEP covered endoprothesis is a good treatment option in palliative situations.

- A single-stage procedure shortens hospitalization time.

Citation Format:

- Scheer F, Wissgott C, Lüdtke CW et al. Single-Phase Percutaneous Recanalization of Malignant Bile Duct Obstructions with a Covered Stent Graft. Fortschr Röntgenstr 2014; 186: 394-399

\section{Zusammenfassung}

$\nabla$

Ziel: Ziel dieser retrospektiven Studie war es, den Benefit einer perkutan transhepatisch implantierten Endoprothese bei Patienten mit tumorbedingter Stenose des DHC und palliativer Therapiesituation zu evaluieren.

Material und Methoden: Bei 32 Patienten (mittleres Alter $72 \pm 13$ Jahre) mit kausal maligner Okklusion des Ductus choledochus (DHC) und frustranem Versuch der endoskopischen retrograden Cholangiopancreaticografie (ERCP) wurde die Indikation zur perkutanen transhepatischen Cholangiodrainage (PTCD) und Implantation einer Endoprothese (VIABIL der Firma M. L. GORE \& ASSOCIATES, INC., USA) gestellt.

Ergebnisse: Die technische Erfolgsrate lag bei 96,9\%. Bei einem Patient war die Sondierung eines intrahepatischen Gallengangs nicht möglich. Zwei Majorkomplikationen (Nachblutung, Leberabszess) konnten durch entsprechende Maßnahmen erfolgreich behandelt werden. Der Gesamtbilirubin war mit 13,2 $\pm 6,5 \mathrm{mg} / \mathrm{dl}$ unmittelbar postinterventionell nicht signifikant erniedrigt $(p>0,05)$. Im Follow-up zeigte sich jedoch eine signifikante Erniedrigung des Gesamtbillirubin auf $6,0 \pm 7,4 \mathrm{mg} / \mathrm{dl}(\mathrm{p}<0,05)$. Bei 9 Patienten wurde die Stentprothese mittels Baremetal Nitinolstents verlängert. Die mittlere 
Überlebenszeit des Patientenkollektivs lag bei $62 \pm 71$ Tagen (range: 2 - 250 Tage).

Schlussfolgerung: Die interventionelle Implantation einer Endoprothese stellt bei Patienten mit maligner Gallengangsobstruktion in einer palliativen Therapiesituation und frustaner endoskopischer Sondierung eine Option mit gutem Benefit dar.

\section{Introduction}

$\nabla$

In the majority of cases, malignant bile duct obstructions represent a palliative situation with an unfavorable prognosis for the affected patient [1]. They can be caused by pancreatic carcinomas, bile duct tumors, or metastases, lymphomas, gallbladder tumors, tumors or the stomach and duodenum, and hepatocellular carcinoma [2, 3]. The primary goal of palliative treatment of malignant bile duct stenoses is to improve symptomatic jaundice and limit the risk of cholangitis and renal and hepatic collateral damage [4]. A further improvement of clinical symptoms can be achieved by supplementary palliative chemotherapy and radiation therapy [3].

Gastroduodenal obstructions usually require bypass surgery, but this is associated with a relatively high mortality rate in palliative situations [4, 5]. Endoscopic and radiological interventional procedures are the treatments of choice for malignant bile duct stenosis with indication for the procedure ideally being determined by a multidisciplinary panel of experts $[2,4]$. In addition to the different interventional procedures, prosthesis materials in the form of plastic or metal stents are available [5].

The goal of this retrospective study was to evaluate the clinical outcome of a percutaneous transhepatic endoprosthesis in malignant occlusion of the common bile duct (CBD) in a palliative treatment situation.

\section{Materials and Methods}

\section{$\nabla$}

The data of 32 patients (average age: $72 \pm 13$ years) with a malignant bile duct obstruction in a palliative treatment situation between 2009 and 2012 were included in this retrospective study. In addition to the primary disease and obstructive jaundice, the inclusion criteria were unsuccessful endoscopic recanalization attempts and the standards for performing minimally invasive image-guided interventions of the German Society of Interventional Radiology and Minimally Invasive Therapy (DeGIR) [6]. Surgical treatment of the bile duct occlusion was not indicated in any of the patients included in the study. The location of the bile duct obstruction was categorized according to the Bismuth classification [7]. The survival and hospitalization time, the serum bilirubin in the follow-up period, interventional complications, the cause of death, and the rate of restenosis were the most important examination parameters of this study. The serum bilirubin was determined in a standardized manner before and one day after intervention. In the follow-up period, the bilirubin value was recorded as a function of the hospitalization time and the ambulant followup examinations. The interventions were performed by three different radiologists with a high level of interventional procedure expertise.

\section{Treatment method}

The access for percutaneous transhepatic cholangiography (PTC) was planned preinterventionally via a plain CT scan of the liver. All patients were treated prophylactically with a single-shot i.v. antibiosis of 2 grams ceftriaxone prior to the intervention. The intervention was performed under sterile conditions and with cardiovascular monitoring of the patient after intravenous analgosedation with $2-5 \mathrm{mg}$ midazolam and local anesthesia with 20-30 ml mepivacaine. After puncture of the bile duct with a $21 \mathrm{G}$ introducer needle and dilation of the access for insertion of a 4.5 French lock (AccuStick from Flexima Biliary ${ }^{\circledR}$ catheter system kit, Boston Scientific), a 0.035" Terumo Stiff guidewire was carefully advanced into the duodenum and the 4.5 French lock was replaced by a 6 French lock (Radiofocus Introducer $2^{\circledR}$, Terumo). PTC was then performed to visualize the length, the location of the bile duct occlusion, and the cystic duct ( $\bullet$ Fig. 1a, b). Pre-dilation of the bile duct stenosis was performed with a 5/80 balloon catheter (Mustang, Boston Scientific) and a change to a 10 French lock (Radiofocus Introducer $2^{\circledR}$, Terumo) with a working length of $25 \mathrm{~cm}$ was made. A self-expanding $8 / 60 \mathrm{~mm}$ ePTFE-FEP (expanded polytetrafluoroethylene fluorinated ethylene propylene) covered stent (VIABIL ${ }^{\circledR}$, W. L. GORE \& ASSOCIATES) was implanted in the region of the CBD with the distal end of the prosthesis extending beyond the papilla of Vater by less than $2 \mathrm{~cm}$. The post-dilation of the VIABIL endoprosthesis
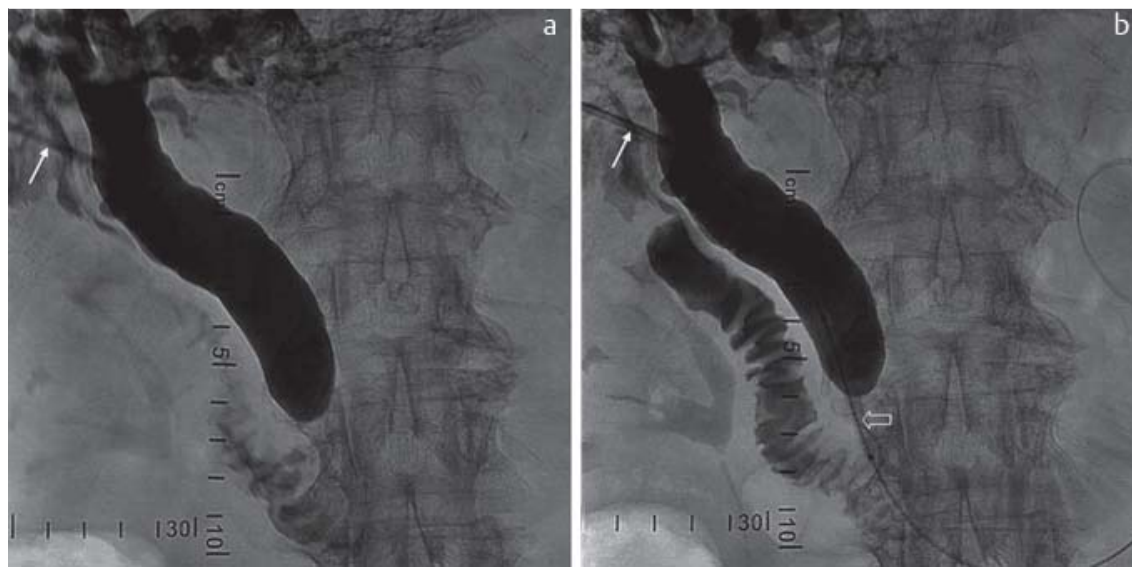

Fig. 1 a, b After probing a bile duct and inserting a working lock (arrow), opacification of the biliary tract and visualization of high-grade stenosis/occlusion of the common bile duct over a length of about $4 \mathrm{~cm}$. After advancing a guidewire into the duodenum, the balloon catheter is positioned (open arrow). 

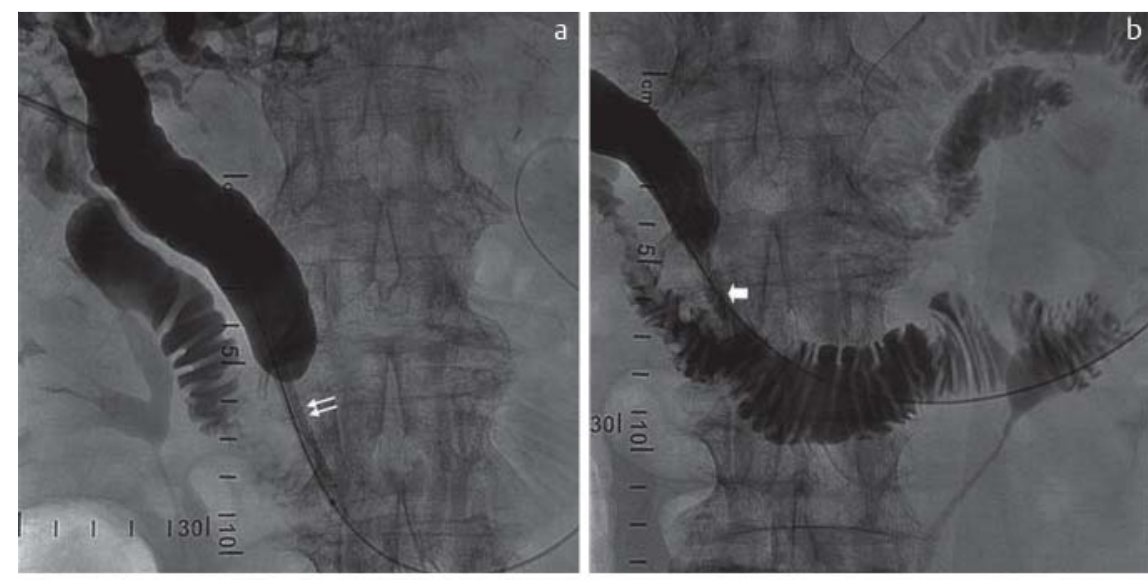

Fig. 2 a, b Balloon dilation of the stenosis (double arrow) and placement of $8 / 60 \mathrm{~mm}$ VIABIL endoprosthesis (thick arrow). $\mathbf{c}$ The modeling of the VIABIL endoprosthesis was performed with a $7 / 80 \mathrm{~mm}$ balloon catheter. $\mathbf{d}$ Outflow of the contrast medium into the duodenum and documentation of technical success.
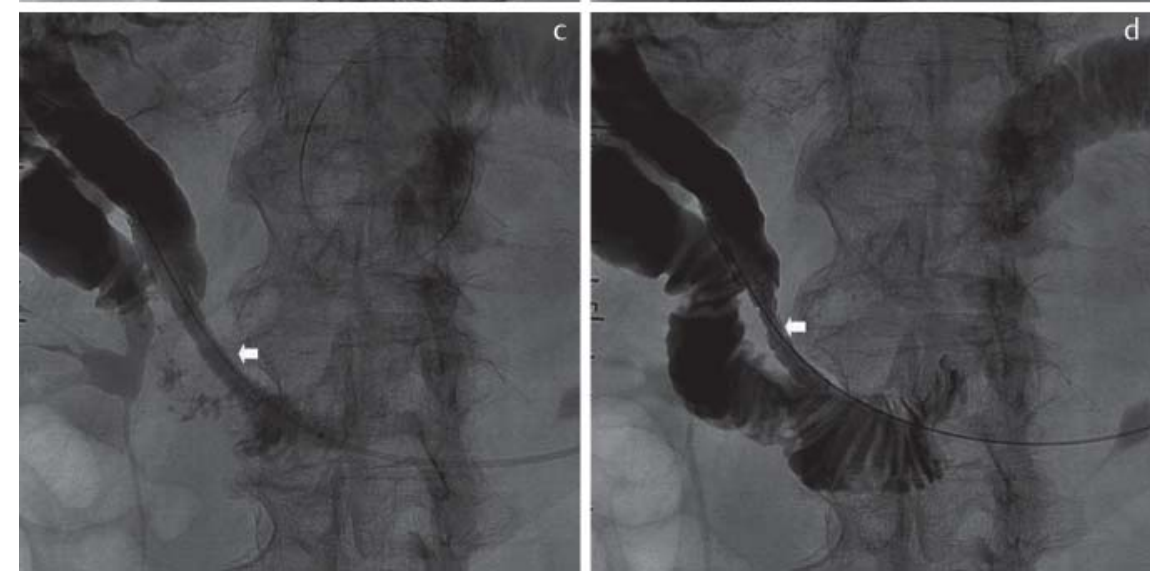

was performed with a balloon catheter with a diameter of $7 \mathrm{~mm}$ and a length of $80 \mathrm{~mm}$ (Mustang ${ }^{\circledR}$, Boston Scientific) ( $\bullet$ Fig. 2a-d).

In the case of very long stenoses of the extrahepatic bile duct, a second VIABIL endoprosthesis with the same nominal diameter and same length was implanted in individual cases. If the bile duct occlusion continued in a central direction into the hepatic fork or in the case of an additional stenosis, a self-expanding nitinol stent (S.M.A.R.T. ${ }^{\circledR}$, Cordis) of varying size was used and post-dilated accordingly ( $\bullet$ Fig. 3a, b). The flow of the contrast medium into the duodenum was documented. Remaining stenosis $<30 \%$ was evaluated as a technical success after angiographic examination.

Follow-up examinations via ultrasound and/or computed tomography were only performed in the case of a recurrence of symptomatic jaundice.

\section{Statistical analysis}

The results of this study are provided as mean \pm standard deviation. The Wilcoxon test was used as a statistical test for comparing quantitative data. The significance level was defined as $<0.05$.

\section{Results}

$\nabla$

In total, a VIABIL endoprosthesis was able to be successfully percutaneously transhepatically implanted in 31 patients. The primary technical success rate was $96.9 \%$. An intrahepatic bile duct could not be probed in one patient.

In 21 of 31 cases the cause of the occlusion was the primary tumor or the primary disease followed by liver metastases in 7 cases and lymph node metastases in 4 of 31 cases. De- 
pending on the length of the bile duct stenosis, two VIABIL endoprostheses were implanted in individual cases using the stent-in-stent technique. Intrahepatic and proximal extrahepatic stenoses were treated with uncovered nitinol stents. The VIABIL endoprosthesis had to be extended proximally by nitinol stents in 10 cases.

The median bilirubin value prior to the intervention was $14.5 \pm 6.5 \mathrm{mg} / \mathrm{dl}$. In the laboratory test one day after the intervention, no significant reduction of the total bilirubin was observed (median $13.2 \pm 6.5 \mathrm{mg} / \mathrm{dl} ; \mathrm{p}>0.05$ ).

However, further follow-up examinations showed a highly significant reduction in the bilirubin value $(\mathrm{p}<0.05)$ to $6.0 \pm$ $7.4 \mathrm{mg} / \mathrm{dl}$ in 30 of 31 patients ( $\bullet$ Fig. 4). In the postinterventional observation period, two patients had significantly increased serum bilirubin values that were higher than prior to the intervention. Hemobilia was diagnosed in both patients in the follow-up examinations and was treated by temporary external percutaneous transhepatic biliary drainage (PTCD). A liver abscess developed postinterventionally in one case and was successfully treated via drainage and i.v. antibiosis. Periinterventional bleeding with a non-clinically relevant drop in hemoglobin did not progress over time. Tumor infiltration of a nitinol stent required a new percutaneous transhepatic cholangiography with probing and balloon dilation of the restenosis in one central bile duct carcinoma ( $\bullet$ Table 1 ). Otherwise, no additional restenosis of the stent implant was seen in the observation period. The average survival time of the patient collective was $62 \pm 71$ days (range: $2-250$ days) with an average total hospitalization time of $14 \pm 11$ days (range: $1-40$ days). 16

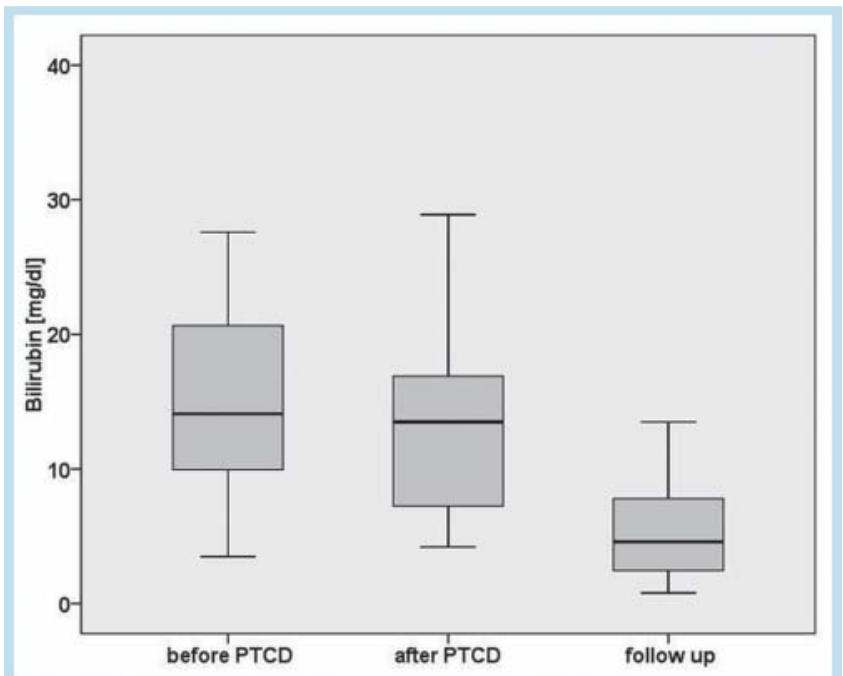

Fig. 4 Significant decrease in follow-up serum bilirubin $[\mathrm{mg} / \mathrm{dL}](p<0.005)$. On average, the time of the follow-up value was 40.4 days ( \pm 47$)$. of 29 patients died within 30 days. The cause of death was unclear in 22 of 29 cases of death at home. The cause of death was cardiac in 5 of 29 patients. One patient died of a pulmonary artery embolism, one of upper gastrointestinal hemorrhage, and one of multiple organ failure due to sepsis. 2 of 31 patients survived to the end of data collection.

\section{Discussion \\ $\nabla$}

During palliative treatment of malignant bile duct stenoses, the primary goals are to reduce symptomatic jaundice and to prevent cholangitis and liver failure [8]. The postinterventional serum bilirubin is an independent predictor for the prognosis of the patient. Brountzos et al. defined the cut-off value for a poor prognosis at $4 \mathrm{mg} / \mathrm{dl}[9,10]$. Compared to benign stenoses, malignant bile duct stenoses are located distal to the liver hilum or in the extrahepatic course of the bile ducts in particular [10]. Pancreatic carcinomas and distal cholangiocellular carcinomas (CCCs) are typical tumors of this bile duct segment. The group of malignant obstructive tumors of the proximal bile ducts and the hilar region includes gallbladder carcinomas, advanced gastric carcinomas, lymphomas, liver metastases, and CCCs [2].

In the case of non-resectable malignant bile duct tumors, PTCD with intrahepatic and/or extrahepatic biliary drainage is indicated in addition to endoscopic recanalization. However, due to the lower complication rate and the lower strain on the patient with successful reduction of jaundice, endoscopic recanalization is considered the primary procedure $[11,12]$.

For the recanalization of inoperable malignant bile duct occlusions, the use of metal stents is considered state of the art [13]. Temporary PTCD without the use of self-expanding stent systems is performed in the case of benign bile duct stenosis [12]. The advantages of self-expanding metal stents compared to plastic stents are the greater inner lumina, the option to use the stent-in-stent technique, lower reocclusion rates, shorter hospitalization times, and the lower cost [13-15]. Fanelli et al. came to the conclusion that ePTFEFEP covered stents provide an effective and feasible means of inner biliary drainage in the case of malignant bile duct obstruction and are resistant to tumor ingrowth but not tumor overgrowth [13]. This complication can be counteracted by overstenting [16]. The disadvantages of covered metal stents are the greater risk of cholecystitis or pancreatitis when overstenting the cystic duct or accessory bile ducts [2]. ePTFE-FEP covered stents were only used in the extrahepatic course of the common bile duct in our study. Stenoses in a more proximal position were treated with uncovered nitinol stents. In individual cases, two VIABIL

\begin{tabular}{|c|c|c|c|c|c|c|}
\hline & \multicolumn{6}{|l|}{ complications } \\
\hline & hemorrhage & hemobilia & abscess & $\begin{array}{l}\text { resteno- } \\
\text { sis }\end{array}$ & sepsis & overall \\
\hline immediate complications within $24 \mathrm{~h}$ & 1 & 0 & 0 & 0 & 0 & 1 \\
\hline $\begin{array}{l}\text { early complications up to } 30 \text { days after } \\
\text { intervention }\end{array}$ & 0 & 2 & 1 & 1 & 1 & 5 \\
\hline late complications $>30$ days & 0 & 0 & 0 & 0 & 0 & 0 \\
\hline
\end{tabular}

Tab. 1 Complications after PTC and stent implantation. 
endoprostheses were implanted prophylactically using the stent-in-stent technique to prevent possible tumor overgrowth. We prefer the single-phase approach with stent implantation and internal biliary drainage since the strain on the patient in a palliative situation and the hospitalization time, which was 14 days on average in this study, can be reduced. Fanelli et al. used a two-phase approach in most cases when implanting ePTFE-FEP covered stents to reduce the risk of hemorrhage and to better determine the location of the bile duct stenosis [13]. External PTCD was performed in two of our patients with hemobilia in order to drain the blood clots. At $97 \%$, the technical success rate of the single-phase approach was within the range presented in the literature which was between $97 \%$ and $100 \%$ $[3,13,17,18]$.

The bilirubin value that was only minimally reduced on average one day after the intervention was not interpreted as stent occlusion but as an expression of the stimulation of the bile duct system. The bilirubin value fluctuations within the first week after stent implantation are not to be interpreted as an indication of stent blockage [3]. The total bilirubin value of the patients, which was determined on average 40 days after the intervention during follow-up, can be discussed as an indication for restenosis. However, this was the last value before death and the most common cause of death was the advanced tumor disease. According to the literature, the patency rates of ePTFE-FEP covered stents are between $28.5 \%$ and $100 \%$ in a period between 3 and 12 months after intervention $[13,16,19]$. In light of the average survival time of 62 days in our patient collective, the development of restenosis is not to be expected.

The mortality rate within the first 30 days after percutaneous implantation of metal stents is between $11.5 \%$ and $36 \%$ according to the literature $[13,20,21]$. The complication rate of percutaneously implanted metal stents ranges between $6 \%$ and $61 \%$ [17, 21 - 23]. Endoscopically implanted stent prostheses have a complication rate of $10 \%$ to $42 \%$ $[21,24]$. In particular, acute $(<24 \mathrm{~h})$ and early (<30 days) complications include sepsis, hemobilia, bile leakage, hemorrhage, cholecystitis, and liver abscess. Late complications (> 30 days) primarily include stent occlusions [3]. Fanelli et al. administered antibiotic prophylaxis before and for 5-6 days after the intervention and did not describe any infection-related complications at a complication rate of $6.5 \%$ [13]. In the majority of cases, the complications of percutaneously implanted bile duct prostheses can be treated conservatively [2]. Of the 4 observed complications that could be attributed to PTCD in the patient collective examined here, only one case of sepsis was lethal. In addition to the progress of the tumor disease, cardiovascular causes of death that could not be linked to the interventional procedure were seen in particular. Restenosis due to tumor overgrowth is a general problem of all stents $[25,26]$ that is minimized by the ePTFE-FEP covered endoprosthesis as a result of its special design with an anchoring system consisting of a loop-shaped metal wire [13]. However, these stents are also not immune to tumor overgrowth and reintervention may be required in individual cases. In addition to prophylactic overstenting using the stent-in-stent technique, recanalization via the laser technique is possible in individual cases [27]. Another possible application of covered stent prostheses in addition to the recanalization of malignant bile duct obstructions could be the occlusion of CBD fistulas or bile duct leaks as a supplement to percutaneous onyx application [28].

\section{Conclusion}

$\nabla$

Single-phase percutaneous implantation of an ePTFE-FEP covered endoprosthesis in inoperable patients with malignant cholestasis in a palliative treatment situation represents a safe and effective alternative method to ERCP. Indication should be determined by interdisciplinary consensus of gastroenterologists, surgeons, and interventional radiologists.

\section{Clinical relevance of the study \\ $\nabla$}

- Percutaneous implantation of an ePTFE-FEP covered endoprosthesis is a good and safe treatment option for malignant bile duct obstruction.

- In palliative treatment situations, the single-phase procedure shortens hospitalization time and improves quality of life.

- In a palliative situation, restenosis is rare in the case of stent prostheses.

\section{References}

1 Thornton RH, Frank BS, Covey AM et al. Catheter-free survival after primary percutaneus stenting of malignant bile duct obstruction. Am J Roentgenol 2011; 197: 514-518

2 Van Delden OM, Laméris JS. Percutaneous drainage and stenting for palliation of malignant bile duct obstruction. Eur Radiol 2008; 18: $448-456$

3 Tapping CR, Byass OR, Cast JEI. Percutaneous transhepatic biliary drainage (PTBD) with or without stenting-complications, re-stent rate and a new risk stratification score. Eur Radiol 2011; 21: 1948-1955

4 Lawson AJ, Beningfield SJ, Krige JE et al. Percutaneous transhepatic selfexpanding metal stents for palliation of malignant biliary obstruction. S Afr J Surg 2012; 50: 54-58

5 Dormann A, Meisner S, Verin $N$ et al. Self-expanding metal stents for gastroduodenal malignancies: systematic review of their clinical effetiveness. Endoscopy 2004; 36: 543-550

6 Heuser $L$. Standards zur Durchführung minimal invasiver bildgesteuerter Eingriffe. www.degir.de

7 Bismuth $\mathrm{H}$, Corlette MB. Intrahepatic cholangioenteric anastomosis in carcinoma oft he hilus of the liver. Surg Gynecol Obstet 1975; 140: $170-178$

8 Khan SA, Thomas HC, Davidson BR et al. Cholangiocarcinoma. Lancet 2005; 366: $1303-1314$

9 Brountzos EN, Ptochis N, Panagiotou I et al. A survival analysis of patients with malignant biliary strictures treated by percutaneous metallic stenting. Cardiovasc Intervent Radiol 2007; 30: 66-73

10 Al-Mofleh IA, Aljebreen AM, Al-Amri SM et al. Biochemical and radiological predictors of malignant biliary strictures. World J Gastroenterol 2004; 10: $1504-1507$

11 Speer AG, Cotton PB, Russel RC et al. Randomized trial of endoscopic versus percutaneous stent instertion in malignant obstructive jaundice. Lancet 1987; 2: 67-62

12 Oberholzer K, Bitton MB, Mildenberger P et al. The current value of percutaneus transhepatic biliary drainage. Fortschr Röntgenstr 2002; 174: $1081-1088$

13 Fanelli F, Orgera G, Bezzi M et al. Management of malignant biliary obstruction: Technical and clinical results using an expanded polytetrafluoroethylene fluorinated ethylene propylene (ePTFE/FEP)-covered metallic stent after 6-year experience. Eur Radiol 2008; 18: 911 -919

14 Lammer J, Hausegger KA, Fluckiger $F$ et al. Common bile duct obstruction due to malignancy: treatment with plastic versus metal stents. Radiology 1996; 201: 167-172 
15 Lee BH, Choe DH, Lee JH et al. Metallic stents in malignant biliary obstruction: prospective long-term results. Am J Roentgenol 1997; 168: $741-745$

16 Schoder M, Rossi P, Ulfacker R et al. Malignant biliary obstruction: treatment with ePTFE/FEP-covered endoprotheses - initial technical and clinical experience in a multicenter trial. Radiology 2002; 225: 35-42

17 Hamy A, d'Allincort A, Paineau J et al. Percutaneus self-expandable metallic stents and malignant biliary strictures. Eur J Surg Oncol 1997; 23: $103-108$

18 Dinkel HP, Triller J. Primary and long-term success of percutaneous biliary metallic endoprotheses (Wallstents) in malignant obstructive jaundice. Fortschr Röntgenstr 2001; 173: 1072-1078

19 Hatzidakis A, Krokidis M, Kalbakis K et al. ePTFE /FEP-covered metallic stents for palliation of malignant biliary disease: can tumor ingrowth be prevented? Cardiovasc Interv Radiol 2007; 5: 950-958

20 Bezzi M, Zolovkins A, Cantisani V et al. New ePTFE/FEP-covered stent in the palliative treatment of malignant biliary obstruction. J Vasc Interv Radiol 2002; 13: 581 - 589

21 Pinol V, Castelis A, Bordas JM et al. Percutaneous selfexpanding metal stents versus endoscopic polyethylene endoprotheses for treating malignant biliary obstruction: randomited clinical trial. Radiology 2002; 10: $321-324$
22 Inal M, Akgul E, Aksungur E et al. Percutaneous placement of biliary metallic stents in patients with malignant hilar obstruction: unilobar versus bilobar drainage. J Vasc Interv Radiol 2003; 14: 1409-1416

23 Indar AA, Lobo DN, Gilliam AD et al. Percutaneous biliary metal wall stenting in malignant obstructive jaundice. Eur J Gastroenterol Hepatol 2003; 15: 915-919

24 Ong TC, Khor JL, Selamat DS et al. Complications of endoscopic retrograde cholangiography in the post MRCP-era: a tertiary center experience. World J Gastroenterol 2005; 11: 5209-5212

25 Thurnher SA, Lammer J, Thurnher MM et al. Covered self-expanding transhepatic biliary stents: clinical pilot study. Cardiovasc Intervent Radiol 1996; 19: 10-14

26 Rossi P, Bezzi M, Salvatori FM et al. Clinical experience with covered Wallstents for biliary malignancies: 23-month follow-up. Cardiovasc Intervent Radiol 1997; 20: 441 - 447

27 Lüdtke CW, Wissgott C, Scheer F et al. Perkutane transhepatische Laserrekanalisation bei einem okkludierten Gallengangsstent. Fortschr Röntgenstr 2013; 185: 579-580

28 Uller W, Müller-Wille R, Loss $M$ et al. Percutaneous Management of Postoperative Bile Leaks with Ethylene Vinyl Alcohol Copolymer (Onyx). Fortschr Röntgenstr 2013, [Epub ahead of print] 